\title{
Stunting is A Reflection of Poor Dietary Diversity Among Adolescent Girls in Rural KONKAN Region (DERVAN-6)
}

\author{
Suvarna Patil ${ }^{1 *}$, Rachana Mohite ${ }^{2}$, Ulka Banvali $^{2}$, Pralobhana Devrukhakar ${ }^{2}$, Dnyaneshwar \\ Jadhav ${ }^{2}$, Omkar Dervankar ${ }^{2}$, Charudatta Joglekar ${ }^{2}$ \\ ${ }^{1}$ Department of Medicine, BKL Walawalkar Hospital and Rural Medical College, Sawarde, Taluka- \\ Chiplun, District-Ratnagiri, Maharashtra 415606, India. \\ ${ }^{2}$ Regional Centre for Adolescent Nutition and Health, BKL Walawalkar Hospital and Rural Medical \\ College, Sawarde, Taluka-Chiplun, District-Ratnagiri, Maharashtra 415606, India.
}

\begin{abstract}
*Corresponding Author: Suvarna N patil, Department of Medicine, BKL Walawalkar Hospital and Rural Medical College, Sawarde, Taluka-Chiplun, District-Ratnagiri, Maharashtra 415606, India. Email dr.suvarnanpatil@gmail.com
\end{abstract}

\begin{abstract}
Adolescence is a crucial period in a life cycle which has far reaching implication in adult life. The diet and nutrition play a very crucial role but little information about nutrition of Indian adolescents is available. This is very crucial especially for girls in reproductive age which can affect her own health as well as the health of next generation. KONKAN area from western Indian state of Maharashtra has witnessed under nutrition for many years. The proportion of anthropometric indicators of under nutrition (underweight, stunting and wasting) is very high. Very little information on diet and nutrition is available. DERVAN cohort is a prospective study among adolescent girls. We recorded anthropometry (weight and height). Dietary diversity among the cohort girls was assessed using dietary diversity score (DDS) designed by the Food and Agricultural Organization and USAID's FANTA project. Threshold score of 5 or more (out of maximum 10) was used as an indicator of minimum dietary diversity. Median age of the girls was 16.6 years and proportion of underweight, stunting and thinness was $28.8 \%, 30.7 \%$ and $56.4 \%$ respectively. Only $3 \%$ girls could achieve minimum dietary diversity. Almost $75 \%$ girls had a dietary diversity score range of 2-3. Among anthropometric indicators, the stunted girls had higher likelihood [odds ratio and 95\% confidence interval: 1.61 (1.12-2.32), p<0.05] of poor dietary diversity.
\end{abstract}

Keywords: Dietary diversity, Nutrition, Adolescent, Stunting, KONKAN

Abbreviations: DDS: dietary diversity score; IOTF: International Obesity Task Force.

\section{INTRODUCTION:}

Adolescence is the stage of life (10-19 years) in which a child transitions into an adult. It is characterized by accelerated growth, sexual maturation and complex psycho-social interactions. There are over 1 billion adolescents in the world, the and half of them live in subSaharan Africa and South Asia, where they form $20-35 \%$ of the population [1-2]. Adolescence is also a period when lifelong adaptive or maladaptive behaviour patterns are established, such as choices about diet, physical activity, and substance use including tobacco and alcohol [3]. It has been suggested that adolescence is also a critical period in which optimal nutrition could mitigate the effects of poor fetal and infant nutrition [4-5]. India, home to more than 1.4 billion people, suffers from a "triple burden" of chronic widespread under-nutrition, over nutrition and micronutrient deficiencies. There is a need for better understanding of the impact of nutrition in adolescence on growth, body composition, physical and mental health. Most adolescents are future parents and will also influence the health of the next generation. Thus adequate diet and nutrition in adolescence might be protective against future health and disease and will also benefit the next generation. India is estimated to have the "second-highest number of undernourished people in the world. KONKAN region of the western Indian state of Maharashtra has witnessed under nutrition at various stages of life for many generations. High prevalence estimates of underweight / thinness/low birth weight suggest inadequate nutrition of the 
population in the postnatal as well as fetal life [6]. But the reports documenting diet, nutrition as well as the macro and micronutrient status of the population in the region are scarce [7-8]. BKL Walawalkar Hospital situated in the region is a tertiary care hospital is catering to the surrounding community for last 25 years. It runs various community programmes with women's health as the main focus. It found high prevalence of anaemia among the adolescent girls of the region [9]. Hospital launched DERVAN cohort study in 2019.

Details of DERVAN cohort have been reported [10]. In brief, 1520 adolescent girls (16-18y age) living in 3 talukas (administrative divisions) of Ratnagiri district of the KONKAN area of the western Indian state of Maharashtra are being recruited. The girls are studied at the recruitment stage for their body composition, nutrition, physical activity, biochemical parameters and cognition. Cohort is expected to be studied for next 20 years.

This manuscript explores dietary diversity among girls of Dervan cohort.

\section{MATERIALS AND METHODS}

Adolescents were brought to our institute for 3day residential camps. They underwent various investigations which included nutritional assessment, anthropometry and blood collection.

\section{Nutritional Assessment:}

Dietary diversity: We calculated dietary diversity score (DDS) designed by the Food and Agricultural Organization and USAID's FANTA project [11] for women of reproductive age (1549 years) which is an indicator whether they have consumed at least five out of ten defined food groups the previous day or night. This score reflects micronutrient adequacy. The ten food groups are 1) Grains or white roots and tubers, and plantains 2) Dark green leafy vegetables 3) Orange coloured vegetables/roots/fruits 4) other vegetables 5)other fruits 6) meat/poultry/fish/sea food/animal organs 7) Eggs 8) milk/milk products 9) beans/peas/lentils 10) nuts/seeds. Indicators score of 1 for each food group was generated if there is consumption from that group. The maximum total possible score was 10. Threshold score of 5 or more was used as an indicator of minimum dietary diversity.

\section{Anthropometry:}

We measured height to nearest $0.1 \mathrm{~cm}$ using portable standiometer (Easy care) and weight to nearest $100 \mathrm{gm}$ using digital scale (OMRON).

Page | 13
Body mass index (BMI) was calculated. Stunting and underweight was defined using WHO growth charts for height, weight [12]. Thinness was defined by the criteria laid out by International Obesity Task Force (IOTF) [13].

\section{Statistical Methods:}

Data has been shown as percentages or median $\left(25^{\text {th }}\right.$ to $75^{\text {th }}$ centiles). Odds ratios (OR) for anthropometric indicators (thinness, stunting and underweight) were calculated.

Ethics: The study was approved by the Institute Ethics Committee of BKL Walawalkar Rural Medical College and Hospital. Our institute ethics committee is registered with the Government of India. Registration code is EC/755/INST/MH/2015/RR-18. Appropriate written informed consent was obtained from those who are 18years old. For those below 18 years of age, written informed consent was obtained from parents of the adolescent girl and written informed assent was obtained from the adolescent girl.

\section{RESUltS}

We have recruited 586 girls in our cohort as of March 2021. The girls had median weight, height and BMI of $40.7 \mathrm{~kg}, 151.5 \mathrm{~cm}$ and $17.6 \mathrm{~kg} / \mathrm{m}^{2}$ respectively (table-1). Almost $1 / 3^{\text {rd }}$ were stunted and substantial portion (56.4\%) could be classified as thin. We found the distribution of items consumed from 10 mutually exclusive food groups which form dietary diversity scale designed by FANTA (table-2). It was heavily dominated by either grains or white roots/tubers $(99.3 \%)$ and beans/peas/lentils (87.5\%). Minimum DDS ( $\geq 5)$ was observed in only $3.1 \%$ (table-3). For our convenience we divided our sample into two groups of those with DDS below 3 and DDS $\geq 3$ (table-4). Those stunted were 1.61 times likely to have DDS <3 than non-stunted. The odds ratios for underweight and thinness were not significant.

\section{DISCUSSION}

This is the first systematic documentation of data on adolescent DDS from KONKAN region which has shown high prevalence of under nutrition indicators (low birth weight, stunting and wasting) for many years [14-15]. DDS across various stages of life has been studied in India. There are reports on children, adolescents and women in reproductive age window [16-18]. A report from a rural cohort study [17] in the state of Maharashtra, adolescents deficient in vitamin b12 had higher likelihood of poor DDS. Poor 
DDS has also been reported among adolescents from Bangladesh [19] and children from China [20]. The DDS from our study is probably the lowest when compared to other reports from India. The main contribution to DDS came either from grains or white roots/tubers and beans/peas/lentils. Contribution by other food groups was so poor that it resulted in very low DDS. Only $3.1 \%$ were able to reach minimum cut point of 5 and nobody beyond 5 . The reasons for poor consumption of other food groups in our region are affordability, unavailability. Only pulses and grains are available throughout the year. The Government of India has launched many ambitious schemes with food security as a main focus. However, a lot still needs to be done on the front of nutrition and food security. The impact of the on-going COVID-19 pandemic has added another dimension and continuous to affect food availability and nutritional status.

\section{CONCLUSION}

The under nutrition observed in KONKAN is reflected in poor dietary diversity and our analysis has shown its impact on stunting which reflects multigenerational under nutrition.

\section{Conflict of Interest:}

None of the authors have any conflict of interest to declare.

\section{Acknowledgments}

The authors would like thank the adolescent girls for their participation in the study. We would also like to thank parents for given consent for the participation of adolescent girls.

\section{REFERENCES}

[1]. www.unicef.org/sowc2011/pdfs/SOWC2011-Main-Report_EN_02092011.pdf

[2]. Cappa C, Wardlaw T, Langevin-Falcon C, Diers J. Progress for children: a report card on adolescents. Lancet. 2012 Jun 23;379(9834):2323-5

[3]. Patton GC, Sawyer SM, Santelli JS, Ross DA, Afifi R, Allen NB, Arora M, Azzopardi P, Baldwin W, Bonell C, Kakuma R, Kennedy E, Mahon J, McGovern T, Mokdad AH, Patel V, Petroni S, Reavley N, Taiwo K, Waldfogel J, Wickremarathne D, Barroso C, Bhutta Z, Fatusi AO, Mattoo A, Diers J, Fang J, Ferguson J, Ssewamala F, Viner RM. Our future: a Lancet commission on adolescent health and wellbeing. Lancet. 2016 Jun
11;387(10036):2423-78.

[4]. Viner RM, Ross D, Hardy R, Kuh D, Power C, Johnson A, Wellings K, McCambridge J, Cole TJ, Kelly Y, Batty GD. Life course epidemiology: recognising the importance of adolescence. J Epidemiol Community Health. 2015 Aug;69(8):719-20.

[5]. Blakemore SJ, Mills KL. Is adolescence a sensitive period for sociocultural processing? Annu Rev Psychol. 2014;65:187-207. doi: 10.1146/annurevpsych-010213-115202. Epub 2013 Sep 6. PMID: 24016274.

[6]. Patil S, Joglekar C, Chavan R, Sonawane S, Modak A and Pendse A. Trends in Malnutrition Indicators from Birth to Adolescence in Rural KOKAN Region of Western India. Int J Nutr Sci. 2020; 5(1): 1041.

[7]. Patil S, Joglekar C, Desai M, Yadav A, Sonawane S, Chavan $\mathrm{R}$ and Mohite $\mathrm{R}$ Nutritional Status and Psychological Impairment in Rural Adolescent Girls: Pilot Data From "KOKAN" Region of Western India. (2018) Front. Public Health 6:160. doi: 10.3389/fpubh.2018.00160

[8]. Patil SN, Joglekar CV, Mohite RB, Surve MM, Sonawane S, Chavan R. Menarche among rural adolescent girls in Dervan (Data from the KONKAN region of the state of Maharashtra, India). J Family Med Prim Care 2020;9:5276-5281 DOI: 10.4103/jfmpc.jfmpc_509_20

[9]. Patil SN, Wasnik V, Wadke R. Health problems amongst adolescent girls in rural areas of Ratnagiri district of Maharashtra, India. Journal of Clinical and Diagostic Research 2009;3:1784-90.

[10]. Patil S, Patil N, Joglekar C,Yadav A, Nilawar A, Banavali U, Bhat R, Dombale V, Warpe B, Mohite R, Joshi K. aDolescent and prEconception health peRspectiVe of Adult Non communicable diseases (DERVAN) : Protocol for rural prospective adolescent girls cohort study in Ratnagiri district of Kokan region of India (DERVAN-1). BMJ Open 2020; 10:e035926.

[11]. Food and Agricultural Organisation of the United Nations \& USAID's Food and Nutrition Technical Assistance III Project

Page | 14 
Stunting is A Reflection of Poor Dietary Diversity Among Adolescent Girls in Rural KONKAN Region (DERVAN-6)

(FANTA) (2016) Minimum Dietary Diversity for Women: A Guide for Measurement. http://www.fao.org/3/ai5486e.pdf

[12]. The WHO Child Growth Standards. http://www.who.int/childgrowth/standards len/ . Accessed February 21, 2020.

[13]. Cole T, Lobstein T. Extended international (IOTF) body mass index cut-offs for thinness, overweight and obesity. Pediatric Obesity (2012) 7:284-294.

[14]. Patil S, Dombale V, Joglekar C, Patil N, Joshi K, Warpe B, Burute P. Is small placenta a risk for low birth weight in KOKAN? (Data from a coastal region in the state of Maharashtra, India). J Dev Orig Health Dis. 2020 Aug 3:1-8.

[15]. Patil S, Joglekar C, Chavan R, Sonawane S, Modak A and Pendse A. Trends in Malnutrition Indicators from Birth to Adolescence in Rural KOKAN Region of Western India. Int J Nutr Sci. 2020; 5(1): 1041.

[16]. Ghosh P, Dasgupta A, Paul B, Roy S, Biswas A, Yadav A. A cross-sectional study on prevalence and determinants of anemia among women of reproductive age in a rural community of West Bengal. J
Family Med Prim Care. 2020 Nov 30;9(11):5547-5553.

[17]. Ganpule-Rao AV, Bhat D, Yajnik CS, Rush E. Dietary diversity scores, nutrient intakes and biomarkers vitamin $\mathrm{B}_{12}$, folate and $\mathrm{Hb}$ in rural youth from the Pune Maternal Nutrition Study. Br J Nutr. 2020 Oct 13:1-8.

[18]. Loukrakpam B, Rajendran A, Madhari RS, Boiroju NK, Longvah T. Dietary adequacy and nutritional status of Meitei community of Manipur, Northeast India. Matern Child Nutr. 2020 Dec;16 Suppl 3(Suppl 3):e13046.

[19]. Islam MR, Rahman SM, Tarafder C, Rahman MM, Rahman A, Ekström EC. Exploring Rural Adolescents' Dietary Diversity and Its Socioeconomic Correlates: A Cross-Sectional Study from Matlab, Bangladesh. Nutrients. $2020 \mathrm{Jul}$ 26;12(8):2230.

[20]. Zhao W, Yu K, Tan S, Zheng Y, Zhao A, Wang P, Zhang Y. Dietary diversity scores: an indicator of micronutrient inadequacy instead of obesity for Chinese children. BMC Public Health. 2017 May 12;17(1):440.

Table1. Anthropometry and associated morbidity $(n=586)$

\begin{tabular}{|l|l|}
\hline Anthropometry & \\
\hline Age (years) & $16.6(16.0-17.3)$ \\
\hline Weight $(\mathrm{kg})$ & $40.7(36.7-45.5)$ \\
\hline \%Underweight & 28.8 \\
\hline Standing Height $(\mathrm{cm})$ & $151.5(148.0-155.7)$ \\
\hline \%Stunted & 30.7 \\
\hline BMI $\left(\mathrm{kg} / \mathrm{m}^{2}\right)$ & $17.6(16.0-19.9)$ \\
\hline$\%$ Thinness & 56.4 \\
\hline
\end{tabular}

Median $\left(25^{\text {th }}-75^{\text {th }}\right.$ centile $)$ or $\%$

Table2. Dietary diversity groups $(n=586)$

\begin{tabular}{|l|l|ll|}
\hline & Dietary diversity groups & n & $\%$ \\
\hline $\mathbf{1 )}$ & Either grains or white roots/tubers & 582 & 99.3 \\
\hline $\mathbf{2})$ & Green leafy vegetables & 123 & 21.0 \\
\hline $\mathbf{3 )}$ & Either orange-coloured vegetables/roots or orange-coloured fruits & 6 & 1.0 \\
\hline $\mathbf{4 )}$ & Other vegetables & 169 & 28.8 \\
\hline $\mathbf{5 )}$ & Other fruits & 22 & 3.8 \\
\hline $\mathbf{6 )}$ & Either meat/poultry or fish/seafood or animal organs & 120 & 20.5 \\
\hline $\mathbf{7 )}$ & Eggs & 62 & 10.6 \\
\hline $\mathbf{8 )}$ & Milk/milk products & 77 & 13.1 \\
\hline $\mathbf{9 )}$ & Beans/peas/lentils & 513 & 87.5 \\
\hline $\mathbf{1 0})$ & Nuts/seeds & 13 & 2.2 \\
\hline
\end{tabular}


Stunting is A Reflection of Poor Dietary Diversity Among Adolescent Girls in Rural KONKAN Region (DERVAN-6)

Table3. Dietary diversity score based on 24 hour recall $(n=586)$

\begin{tabular}{|c|c|}
\hline DDS score distribution & $\mathrm{n}(\%)$ \\
\hline 0 & $3(0.5 \%)$ \\
\hline 1 & $6(1.0 \%)$ \\
\hline 2 & $202(34.5 \%)$ \\
\hline 3 & $241(41.1 \%)$ \\
\hline 4 & $116(19.8 \%)$ \\
\hline 5 & $18(3.1 \%)$ \\
\hline DDS $\geq 5$ & $18(3.1 \%)$ \\
\hline
\end{tabular}

DDS: Dietary Diversity Score

Table4. Anthropometric morbidities and dietary diversity

\begin{tabular}{|c|c|c|c|}
\hline Outcome & $\begin{array}{c}\text { DDS }<3 \\
(\mathrm{n}=211)\end{array}$ & $\begin{array}{c}\text { DDS } \geq 3 \\
(\mathrm{n}=375)\end{array}$ & Odds ratio with 95\% CI \\
\hline \multicolumn{3}{|l|}{} & \\
\hline Anthropometry & $112 / 94$ & $213 / 157$ & $0.88(0.62-1.24)$ \\
\hline Thinness (Yes/No) & $77 / 129$ & $100 / 270$ & $1.61(1.12-2.32)^{*}$ \\
\cline { 4 - 5 } Stunting (Yes/No) & $60 / 146$ & $106 / 264$ & $1.02(0.70-1.49)$ \\
\hline
\end{tabular}

CI: confidence interval, DDS: dietary diversity score, *: Statistically significant odds ratio

Citation: Suvarna Patil*, Rachana Mohite, Ulka Banvali, et.al. Stunting is A Reflection of Poor Dietary Diversity Among Adolescent Girls in Rural KONKAN Region (DERVAN-6). ARC Journal of Journal of Nutrition and Growth. 2021; 7(1): 12-16. DOI: https://doi.org/10.20431/2455-2550.0701002.

Copyright: (1) 2021 Authors. This is an open-access article distributed under the terms of the Creative Commons Attribution License, which permits unrestricted use, distribution, and reproduction in any medium, provided the original author and source are credited. 